\title{
Las marcas de lo religioso en la política sexual: debate legislativo y matrimonio entre personas del mismo sexo en Argentina
}

\author{
María Candelaria Sgró Ruata \\ Doctoranda en Estudios Sociales de América Latina (Universidad Nacional de Córdoba) \\ candelariasgro@hotmail.com \\ Juan Marco Vaggione \\ Doctor en Sociología y en Derecho (Universidad Nacional de Córdoba) \\ Profesor de la Universidad Nacional de Córdoba \\ juanvaggione@yahoo.com
}

\begin{abstract}
Resumen Los debates públicos sobre sexualidad y reproducción ponen en escena con mayor intensidad los complejos entramados entre lo religioso y lo político en nuestras democracias contemporáneas.

Este artículo se propone indagar la presencia de lo religioso en el debate parlamentario sobre matrimonio entre personas del mismo sexo en Argentina (2010) y analizar los sentidos desplegados en las intervenciones legislativas para comprender las (re)articulaciones entre religión y política.

Poner en cuestión la heteronormatividad de la institución matrimonial implica también poner en tensión, visibilizar, su genealogía cristiana. De esta manera, el debate parlamentario se vuelve un escenario privilegiado para abordar el poder político de las religiones. La perdurabilidad política de lo religioso desafía los análisis sobre la sexualidad no solo porque es un área de incipiente debate en América Latina sino porque lo sexual constituye una arena sobre la cual las principales instituciones religiosas no están dispuestas a resignar su influencia social y política.
\end{abstract}

Palabras-clave: sexualidad, religión, debate parlamentario, matrimonio entre parejas del mismo sexo.

\section{Introducción}

T uego de déCAdas de activismo en Latinoamérica, los movimienL tos feministas y por la diversidad sexual inauguraron una nueva etapa en la política sexual caracterizada por la creciente legitimidad de sus demandas. Tal como lo evidencian distintas encuestas ${ }^{1}$ realizadas en los últimos años en la región, existe un destacado apoyo de la ciudadanía al reconocimiento de diferentes prácticas sexuales y reproductivas como la anticoncepción, la interrupción voluntaria de emba-

1. En Argentina, ver Mallimaci; Esquivel; Irrazabal (2008). Oros trabajos abordan datos a nivel comparativo entre diferentes países de la región: para los casos de Brasil, Chile, México y Nicaragua, se puede consultar Dides, et al. (2011) y para los de Bolivia, Colombia y México, CDD (2003) 
razos, las identidades sexuales diversas, entre otras. Esta legitimidad también se materializa en los debates y reformas legales dirigidos a ampliar el espacio para los derechos sexuales y reproductivos (DDSSRR). En algunos países se han ido reconociendo derechos que extienden los márgenes de libertad y autonomía en decisiones vinculadas a la sexualidad y la reproducción. La educación sexual, el acceso universal a la anticoncepción, los derechos para las personas LGBT o la despenalización del aborto, entre otros, han comenzado a ser parte de los sistemas legales. ${ }^{2}$

Uno de los aspectos más relevantes y conflictivos de esta nueva etapa es el reconocimiento de derechos a las parejas del mismo sexo. Sea por medio de decisiones judiciales o debates legislativos, distintos países modifican sus marcos legales poniendo en cuestión la complementariedad de los sexos como requisito indispensable para el reconocimiento de vínculos conyugales y/o de parentesco (Grossi, et al., 2007; Uziel, 2007; Aldao, et al., 2010). El poder judicial ha sido un órgano del Estado relevante respecto a estas modificaciones ya que varios fallos de la región se han pronunciado a favor de cuestiones inmigratorias, visitas íntimas carcelarias, derechos económicos o de adopción, debilitando, así, la heteronormatividad del sistema legal (Vaggione, 2008a). También estos derechos se han reconocido por medio de debates legislativos. En este sentido, el primer antecedente en Argentina se produjo en el año 2002 cuando la Ciudad de Buenos Aires, otorgó derechos a las uniones civiles como institución conformada por dos personas con independencia de su sexo u orientación sexual, al que siguieron medidas similares en otros países. Otro antecedente importante fue la reforma del Distrito Federal de México de fines del 2009 cuando se permitió el casamiento entre personas del mismo sexo. Finalmente, el caso de Argentina, objeto de análisis de este artículo, reforma el derecho de familia en el año 2010 reconociendo el derecho al matrimonio para parejas del mismo sexo en todo el territorio nacional.

El debate sobre estos derechos vuelve visible, entre otras cuestiones, los complejos entrecruzamientos entre religión y política que caracterizan a las democracias contemporáneas. ${ }^{3}$ Como se propone analizar en este artículo, debatir derechos para parejas del mismo sexo requiere, de manera directa o indirecta, entender las (re)articulaciones entre lo político y lo religioso. Las demandas a favor de los DDSSRR en general y de las parejas del mismo sexo, no solo ponen de manifiesto la fuerte influencia de las instituciones religiosas -en particular, la Iglesia católicasobre el Estado y la construcción del derecho, sino que también generan una intensificación en las posturas integristas y conservadoras de sectores católicos y evangélicos principalmente. ${ }^{4}$ La sexualidad es, probablemente, la arena más resistente a la limitación del poder político de las religiones. En el caso específico del matrimonio, más allá de la secularización de la que fue objeto sobre todo a fines del siglo XIX, continúa siendo una institución que preserva una herencia cristiana. Cuestionar la heteronormatividad de la institución es volver visible, aún más, esta genealogía religiosa. A esto se agrega que modificar el derecho para legitimar las parejas del mismo sexo implica revertir la delegación de los Estados en la Iglesia católica las cuestiones relacionadas con la familia. ${ }^{5}$

Como se profundiza a continuación, reconstruir legalmente la institución matrimonial requiere suspender las formas naturalizadas de pensar los vínculos entre lo religioso y lo político y observar (re)articulaciones alternativas. De esta manera y aun cuando las influencias políticas de lo religioso se manifiestan en diferentes ámbitos (Peñas Defago y Vaggione, 2011; Sgró Ruata, et.al., 2011), el debate parlamentario sobre "matrimonio igualitario" en Argentina (2010) ofrece un escenario privilegiado para su observación. Tomando los discursos de los/as legisladores/ as como material para el análisis, el artículo persigue dos propósitos específicos. En primer lugar, identificar la presencia de lo religioso en las intervenciones legislativas. A partir de este primer acercamiento planteamos algunas relaciones en torno a las sesiones legislativas y presentamos una categorización de las diversas maneras en las que lo religioso adquiere pre-

\footnotetext{
2. En Argentina, por ejemplo, durante la última década se sancionaron diferentes leyes a nivel nacional en relación con derechos sexuales y reproductivos, tales como: Ley 25.673 de Salud Sexual y Procreación Responsable (2002), Ley 26.150 de Educación Sexual Integral (2006); Ley 26. 618 de reforma del Código Civil sobre matrimonio entre personas del mismo sexo (2010); Ley núm. 26. 743 de Identidad de Género (2012). Procesos similares relacionados con el reconocimiento de derechos a parejas del mismo sexo o de despenalización-liberación del aborto se dieron en otros países de América Latina como por ejemplo, en México, Colombia y Brasil.

3.Con relación a debates sobre política y religión, se puede consultar Da Costa (2006); Mallimaci (2008); Blancarte (2008).

4. En América Latina, la Iglesia católica es la que recibe prioridad analítica en los procesos de discusión de políticas públicas y debates legislativos sobre DDSSRR. Al respecto se puede consultar Dides (2004); Guzman Stein (2001). Más específicamente, sobre los vínculos entre Iglesia Católica y los Estados latinoamericanos, Huaco Palomino (2008); Nugent (2004); Htun (2003), Vasallo (2005); González Ruiz, (2005); Mujica (2007). Sin embargo, en las últimas décadas el incremento del pentecostalismo en la región generó el interés por analizar el rol de las instituciones evangélicas, muchas de las cuales se han alineado a la posición sostenida por la Iglesia católica en oposición a la despenalización del aborto o al matrimonio de parejas del mismo sexo. En este sentido, se puede consultar, Cuoto (2005); Machado (2003; 2006).
}

6. En América Latina en general, este proceso transitó un capítulo importante con la legalización del divorcio vincular; el requisito de la complementariedad de los sexos renueva el desafío para la profundización de la laicidad de los poderes estatales. 
sencia en el debate parlamentario. En segundo lugar y con el objetivo de profundizar el abordaje, realizamos un análisis de las intervenciones parlamentarias para comprender las formas en que religión y política se (re)articulan frente al debate por el matrimonio igualitario. En esta instancia buscamos indagar las maneras en las que se relacionan los sentidos desplegados en los discursos legislativos con su contexto sociopolítico de producción.

A través de estos análisis, el artículo contribuye al debate sobre los roles públicos de las religiones considerando la sexualidad, probablemente, la arena más compleja para la indagación. Como se explicita a continuación, la perdurabilidad política de lo religioso desafía de manera particular los análisis sobre la sexualidad ya que no solo es un área de incipiente debate en la región sino que lo sexual constituye una arena sobre la cual las principales instituciones religiosas no están dispuestas a resignar su influencia social y política.

\section{Lo religioso en el espacio público}

El papel de las religiones en política es uno de los principales debates de las ciencias sociales contemporáneas. Por décadas la construcción de la modernidad como proceso de diferenciación de esferas y de exclusión de lo religioso del campo político circuló de manera hegemónica en las ciencias sociales desplazando el interés por el fenómeno religioso como dimensión política (Casanova, 1994). Sin embargo, la fuerte presencia de lo religioso en la mayoría de las regiones del mundo produce un escenario de creciente interés académico en torno a la comprensión de los actores y discursos religiosos como una dimensión pública en las políticas nacionales e internacionales. ${ }^{6}$

Este "retorno a" lo religioso implica, entre otras cuestiones, un regreso a la preocupación prescriptiva sobre la legitimidad (o falta de ella) de las religiones para ser parte de los debates públicos. Frente a la indudable influencia de las religiones en la toma de decisiones sobre diferentes aspectos (la sexualidad es uno de los más relevantes) el interrogante se vuelca hacia la legitimidad de dicha influencia.

De esta forma, se encuentran posturas de carácter restrictivo que defienden la exclusión de lo religioso de la arena política puesto que lo consideran como un sistema de creencias que debe limitarse a la esfera privada. ${ }^{7}$ Desde esta perspectiva, se presenta la secularización como un proceso que debe ser profundizado en las sociedades contemporáneas para demarcar claramente lo religioso de lo secular o la laicidad como una forma de construcción de lo público que implica la exclusión de lo religioso. ${ }^{8}$

Sin embargo, en los últimos años se ha comenzado a revisar críticamente la postura que reduce la legitimidad de lo religioso a la esfera privada. Frente a la indiscutible supervivencia de lo religioso en la modernidad y a su multiplicidad de funciones, se vuelve indispensable repensar las fronteras trazadas sobre lo religioso ampliando su legitimidad como dimensión de la política contemporánea. En este sentido, es posible encontrar diversas relecturas sobre las fronteras de lo público que amplían, de formas diversas, la legitimidad de lo religioso. Por ejemplo, ciertos abordajes críticos a la herencia occidental secularista consideran la artificialidad de la distinción entre lo religioso y lo secular, y, en consecuencia, sostienen la no exclusión de lo religioso (tanto actores como discursos) del espacio público en general (Connolly, 1999; Asad, 2003).

También es posible encontrar posturas intermedias desde las cuales se reconoce la legitimidad de lo religioso como una dimensión pública de la sociedad civil pero se lo excluye de la sociedad política. En este sentido, las discursividades religiosas pueden circular en los debates de la ciudadanía pero los debates legislativos deben, en cambio, ser sostenidos solo desde la utilización de discursos seculares ya que son los únicos que permiten el diálogo y un potencial acuerdo. ${ }^{9}$ Sin abandonar completamente el paradigma de la secularización o de la laicidad, estas propuestas reconocen una mayor legitimidad a lo religioso como clivaje político.

\footnotetext{
6. Son diversos los trabajos académicos publicados en los últimos años que incluyen debates sobre lo religioso a nivel de políticas nacionales e internacionales. Sirva como ejemplo la compilación de Vries y Sullivan (2006) en la cual los principales académicos sobre la política debaten la cuestión religiosa.

7. Las concepciones liberales de democracia tienden a excluir lo religioso como dimensión pública y reafirmar el carácter de privado de las creencias religiosas. Para un análisis influyente ver Rawls (1995).

8. Reconocemos, por supuesto, que hay diversas versiones y formas de definición tanto de la secularización como de la laicidad pero ambas sirvieron hasta hace relativamente poco tiempo como construcciones para reforzar la necesidad de privatizar lo religioso como parte de las políticas democráticas.

8. Reconocemos, por supuesto, que hay diversas versiones y formas de definición tanto de la secularización como de la laicidad pero ambas sirvieron hasta hace relativamente poco tiempo como construcciones para reforzar la necesidad de privatizar lo religioso como parte de las políticas democráticas.

9. Habermas, en sus más recientes trabajos, diferencia la presencia pública de lo religioso a nivel de la sociedad civil (que acepta porque enriquece la pluralidad de voces) de la sanción y aplicación del derecho donde insiste en la necesidad de un filtro institucional que excluya lo religioso. Ver Habermas (2006).
} 
Estos debates sobre los roles públicos de las religiones en las democracias contemporáneas desafían de manera particular los estudios sobre la sexualidad. La sexualidad es una arena en la cual el trazado de las fronteras entre lo religioso y lo secular así como la exclusión de las religiones de la esfera pública son dos operaciones no solo complejas sino de alguna manera imposibles. Al debatirse los DDSSRR es inevitable la presencia pública de lo religioso como una de las principales dimensiones de la política sexual. Así lo manifiestan diversos análisis que van desde considerar las instituciones religiosas como el principal obstáculo para los movimientos por la diversidad sexual (relación de "enemigos perfectos ${ }^{10}$ ") a los abordajes que, por el contrario, consideran diferentes articulaciones entre las tradiciones religiosas y las posturas de los movimientos feministas y por la diversidad sexual. ${ }^{11}$ Este artículo contribuye, precisamente, al debate sobre religión y política sexual al considerar las intervenciones legislativas que precedieron a la aprobación del matrimonio para las parejas del mismo sexo en Argentina. A pesar de que los estudios sobre las interconexiones entre religión y sexualidad se han incrementando (Vaggione, 2009a), un aspecto con escasa exploración en los análisis realizados en la región es comprender las formas en que lo religioso se vuelve materialidad discursiva en los debates parlamentarios sobre DDSSR R..$^{12}$ Más allá de las formas en que actores e instituciones religiosas buscan influenciar al poder legislativo (Vaggione, 2010; Peñas Defago y Vaggione, 2011) interesa sin embargo analizar las formas en que los/as legisladores/as refieren, de algún modo construyen, lo religioso en el momento de debatir políticamente sobre la sexualidad en las democracias contemporáneas.

\section{El debate parlamentario}

En el mes de mayo de 2010 adquiere media sanción en la Cámara de Diputados el proyecto de ley para la modificación del Código Civil argentino que propone el reconocimiento de la institución matrimonial a parejas conformadas por personas del mismo sexo. En el mes de julio y luego de un extenso debate en la Cámara de Senadores, el proyecto es aprobado y se convierte en ley (Num. 26.618). ${ }^{13}$

La incorporación en la agenda pública de la demanda por el "matrimonio igualitario" generó de manera inmediata una fuerte presencia pública de actores y discursos religiosos que, en general, reaccionaron en oposición a la demanda. Encabezada por la jerarquía católica, esta reacción también tuvo como actores relevantes a las jerarquías del campo evangélico bíblico-conservador (Jones y Cunial, 2011) y a sectores de la población fuertemente involucrados con estas tradiciones religiosas (Sgró Ruata et al., 2011).

Al ponerse en discusión la (no) necesariedad del requisito de complementariedad de los sexos para contraer matrimonio, se pone en cuestión, al mismo tiempo y de maneras más o menos directas, lo religioso como un clivaje político en las sociedades contemporáneas. Más allá del proceso de secularización, la influencia católica es constitutiva de los contornos culturales y legales sobre los que se construye el concepto de familia desde el Estado y el derecho. Por esta razón, regular la definición de familia inscripta en el derecho implica también repensar las influencias religiosas sobre la política sexual.

Uno de los propósitos de este trabajo es identificar la presencia de lo religioso en el debate parlamentario. Así, el interrogante inicial de este artículo gira en torno a ¿cómo lo religioso ingresa -e impacta- en el debate parlamentario? Más precisamente, ¿cómo se da la presencia de lo religioso en las intervenciones de las/os legisladoras/es? Con estos interrogantes como disparadores presentamos algunas indagaciones que sirven como puerta de ingreso al análisis (apartado III.a). Posteriormente, buscamos profundizar el abordaje haciendo foco en algunos de los sentidos articuladores de los discursos legislativos y sus relaciones con el contexto sociopolítico de producción (apartado III.b).

\section{III. a. Mapeando la/s presencia/s}

Reconociendo la complejidad de cualquier definición sobre lo religioso, incluso la artificialidad de las mismas fronteras entre lo religioso y lo secular (Connolly, 1999), nuestro objetivo no es proveer una definición de lo religioso, sino dar cuenta, de manera inductiva, de las huellas de su presencia a partir de ciertas marcas identificadas en el discurso parlamentario.

Entendemos por "marcas" la presencia en la superficie textual (o materia significante) de procesos de asignación de sentido en un contexto de social de pro-

10. Gallgher y Bull (2001) utilizan esta noción para analizar el antagonismo entre la derecha religiosa y el movimiento por la diversidad sexual. 11. Sin dudas una de las más relevantes es la proveniente de la teología feminista y de la diversidad sexual cuyas lecturas proponen una deconstrucción y reinterpretación de las posturas oficiales de las iglesias. Ver por ejemplo, Althaus-Reid (2001); Musskopf (2005).

12. En Brasil es donde existen mayores antecedentes del estudio de la religión como dimensión en los debates políticos y, en particular, parlamentarios. Se puede consultar, por ejemplo, Machado (2006); Campos Gómes (2009). Para un estudio sobre Argentina y el debate legal sobre "matrimonio igualitario", ver Vaggione (2011).

13. Promulgada por el Poder Ejecutivo de la Nación el 21 de julio de 2010. 
ducción (Verón, 1993). De allí que si consideramos que los discursos contienen las "huellas" de sus condiciones sociales de producción, es decir, su relación con otros discursos presentes en su contexto socio-histórico y político de generación, es posible acceder a estas relaciones a partir de ciertas "marcas" inscriptas en los textos (Verón, 1993). De esta_manera, y en función de las consideraciones precedentes, construimos una categoría operativa que denominamos "dimensión religiosa en sentido amplio" que utilizamos para identificar aquellas intervenciones en las que fue posible reconocer alguna relación con un cuerpo de discursos del orden de lo religioso mediante la detección de ciertas marcas presentes en los materiales. ${ }^{14}$

Este primer acercamiento permitió advertir la significativa presencia de lo religioso en el discurso parlamentario: un 63\% de las intervenciones de diputados y un $86 \%$ de las intervenciones de senadores incluyen o hacen referencia a lo religioso (en sentido amplio). Estos datos nos permiten decir que la mayoría de los legisladores de ambas cámaras realiza algún tipo de referencia a lo religioso en algún momento de su intervención.

Asimismo, la mayor proporción de marcas religiosas detectadas en senadores en relación con las de diputados, puede deberse a que en el periodo posterior a la media sanción en la Cámara de Diputados las instituciones religiosas (en particular la jerarquía católica y la evangélica) comenzaron a manifestarse con mayor virulencia en el espacio público. Como lo afirmáramos previamente, al debatirse derechos sexuales o reformarse la concepción de familia sostenida desde el derecho, se debate también, de manera directa o indirecta, lo religioso como dimensión de la política contemporánea.

Ahora bien, nos interesa detenernos en la relación existente entre la posición definitiva adoptada por los participantes (voto a favor o en contra del proyecto) y la presencia de la dimensión religiosa en sus intervenciones. Del cruce de estas dos condiciones observamos que en ambas cámaras legislativas, la presencia de marcas religiosas se produce mayoritariamente entre quienes votaron a favor de la reforma legal. Así vemos que de los diputados que presentan marcas religiosas en sus intervenciones, el 66\% votó a favor de la ley mientras que el $32 \%$ lo hizo en contra. En la misma dirección, en el caso de senadores, el 56\% de quienes presentan marcas religiosas en sus intervenciones votó a favor de la ley mientras que el $38 \%$ lo hizo en contra. ${ }^{15}$

Estas relaciones permiten ver que las intervenciones con marcas religiosas no determinan una posición respecto al proyecto de ley, al contrario, lo religioso adquiere presencia tanto en quienes se manifiestan a favor como en quienes lo hacen en contra. Sin embargo, y no es menor, la presencia de lo religioso cobra mayor relevancia en las intervenciones de quienes se manifiestan a favor de la modificación del Código Civil habilitando el matrimonio entre parejas del mismo sexo. Esto requiere profundizar el análisis para conocer cómo sentidos del orden de lo religioso atraviesan las intervenciones de los legisladores con posiciones favorables al proyecto de ley, cuestión que abordamos en el apartado siguiente.

Si por un lado este primer análisis nos permitió advertir la fuerte presencia de la dimensión religiosa en el debate, por otro también posibilitó reconocer que lo religioso aparece de diferentes formas. La agrupación de estas a partir de núcleos referenciales nos condujo a la construcción de la categorización ${ }^{16}$ que presentamos a continuación, cuyo objetivo central es mostrar las marcas de presencia de lo religioso en las intervenciones legislativas. Como señalamos antes, lo religioso está presente en el debate parlamentario, importa en esta instancia, entonces, desentrañar las principales formas que adquiere esta presencia.

Un primer núcleo al que denominamos "referencias institucionales" agrupa referencias relativas a las instituciones religiosas a nivel general (las instituciones como entidades) y a nivel particular (sus miembros). Los planos de generalidad-particularidad se funden con los planos instituciones-miembros. De esta manera, por ejemplo, referencias en torno a la institución "iglesia" adquieren singularidad -como Iglesia "católica"- y generalidad -mediante la referencia a la/s Iglesia/s, es decir, sin particularizar en alguna religión- (aun cuando el peso de la Iglesia católica es significativo en relación con las escasas referencias

\footnotetext{
14. Las permeabilidades de las fronteras entre lo religioso y lo político en el campo de la sexualidad, justamente en alineación con las diversas maneras en las que se producen sus articulaciones, plantea la necesidad de discutir y decidir herramientas analíticas que nos permitan el acceso a estas zonas complejas atendiendo a sus entrecruzamientos. Por esta razón, en esta primera instancia de análisis, construimos una categoría operativa que denominamos "dimensión religiosa en sentido amplio" que implica una operación en términos de presencia/no presencia, sin considerar los sentidos puestos en circulación en las intervenciones. Sobre esta base, abordamos las intervenciones legislativas y realizamos marcas en aquellos fragmentos en los que encontramos alguna relación con lo religioso. Este trabajo fue realizado con la asistencia del software para análisis de datos cualitativos Atlas.ti, el que utilizamos para esta y las actividades subsiguientes, puesto que es una herramienta que facilita la organización, codificación, tratamiento y sistematización del material textual.

15. En ambas cámaras, los porcentajes restantes corresponden a abstenciones. Vale decir que en el caso de la Cámara de Senadores, tomamos la votación del dictamen de minoría que propone dar la sanción definitiva al proyecto con media sanción en Diputados.

16. Estos surgen del trabajo con los materiales y, por tanto, no son excluyentes. Asimismo, en esta instancia optamos por la nominación "referencias" de acuerdo con la noción de marcas, es decir, para dejar asentado que se trata de indicadores textuales.
} 
a las demás religiones). En la misma dirección, las referencias a miembros de la/s Iglesia/s; por ejemplo, se nombra a un obispo identificado de la Iglesia católica o a "los obispos", "los prelados", sin identificar alguno en particular. Por ejemplo:

¿Hablamos del matrimonio concebido en la Edad Media como una herramienta o instrumento legal que institucionalizaba las concepciones, filosofías y dogmas de la Iglesia Católica Apostólica Romana? ${ }^{\text {17 }}$

[...] Personajes como monseñores Tortolo, Medina y Quarracino, que bendecían a la represión [...]. ${ }^{18}$

El núcleo "referencias doctrinales" implica la alusión a textos oficiales emitidos por las instituciones religiosas. Así por ejemplo, consideramos las referencias a textos sagrados ("la palabra de Dios", los "textos revelados"), cartas o declaraciones de conferencias episcopales, encíclicas papales, así como también referencias en forma de citación (directa o indirecta) de los pronunciamientos realizados por miembros o autoridades institucionales (como por ejemplo, las declaraciones de un cura, obispo o pastor en los medios de prensa). Por ejemplo:

[...] El derecho más importante que tienen los seres humanos, el derecho que según esa misma génesis nos ha otorgado el Dios de la Biblia, es el de elegir $[\ldots] .{ }^{19}$

[...]Para concluir, voy a citar a Su Santidad el papa Benedicto XVI, cuando era prefecto de la Congregación para la Doctrina de la Fe [...]. ${ }^{20}$

El tercer núcleo que denominamos "referencias de identificación" agrupa construcciones que remiten a identificaciones personales-individuales o socialescolectivas cuyos referentes están conectados con alguna religión. Esto incluye cuando el enunciador se identifica personalmente con alguna religión o figura mítica (como por ejemplo, Jesús, Virgen etc.) o cuando identifica al conjunto de la sociedad con algún precepto religioso tanto a nivel de los cuerpos normativos del Estado (como la Constitución Nacional) o a nivel de configuraciones culturales/costumbres (mediante el uso de nociones como "cultura nacional" conectada a preceptos religiosos como los mandamientos o los sacramentos). Por ejemplo:

[...] y que porque soy católica y cristiana, adhiero profundamente a la fe religiosa y a los principios fundamentales que, para mí, tiene el cristianismo $[\ldots] .{ }^{21}$

[...] Pero fíjense que este Estado nació al amparo de Dios, que es fuente de toda razón y justicia [.... ${ }^{22}$

Por último, construimos una categoría a la que denominamos "referencias de demarcación" que nos permite considerar todas aquellas referencias que no mantienen un vínculo directo con lo religioso pero que, sin embargo, lo convocan a través del trazado de sus fronteras. Así, por ejemplo, este núcleo se encuentra integrado por alusiones a la noción de laicidad y sus derivados (laico, laica, entre otras) en tanto significante que se actualiza y es convocado en las intervenciones parlamentarias. Esta categoría, por tanto, habilita una serie de modalidades de referencia cuya inscripción deviene de las relaciones indirectas que estas mantienen con el campo de discursividades religiosas. Algunos ejemplos ilustrativos son:

[...] No abordamos el matrimonio católico, no abordamos el matrimonio de la religión judía, no abordamos el matrimonio de los musulmanes. Repito: estamos tratando leyes civiles en un Estado laico [.... ${ }^{23}$

[...] Yo tengo mis creencias religiosas pero estas no me impiden tener la certeza de que vivimos en un Estado laico, y en un Estado laico todos tenemos derecho a la igualdad ante la ley, más allá de nuestras creencias $[\ldots] .{ }^{24}$

[...] Este es un debate que se da en este proyecto, que seguramente puede quedar para un futuro. Estas son las cosas que ha traído el debate de este proyecto de ley; el Estado laico, la nueva institución matrimonial, las nuevas familias y los cambios sociales en la República Argentina [...]. ${ }^{25}$

\footnotetext{
17. Silvia Vázquez (diputada, provincia de Buenos Aires).

18. Miguel Pichetto (senador, provincia de Río Negro)

19. Silvia Vázquez (diputada, provincia de Buenos Aires).

20. Julio Ledesma (diputado, provincia de Buenos Aires).

21. Lucía Corpacci (senadora, provincia de Catamarca).

22. José Mayans (senador, provincia de Formosa).

23. Vilma Ibarra (diputada, Ciudad Autónoma de Buenos Aires).

24. Lorena Rossi (diputada, provincia de Río Negro).

25. Gerardo Morales (senador, provincia de Jujuy).
} 
Ahora bien, dado que estos datos solo consideran marcas de presencia de lo religioso en las intervenciones, es necesario avanzar en el análisis para profundizar los sentidos articulados en los discursos como manera de acceder a las significaciones desplegadas, es decir, como manera de abordar las tensiones entre lo político y lo religioso.

\section{III. b. Voces}

En la sección anterior buscamos poner en evidencia la presencia de lo religioso en el debate parlamentario a partir de la detección de diferentes formas de referencia, las que agrupadas en núcleos referenciales nos permitió descomponer lo que denominamos dimensión religiosa en sentido amplio. Tal y como lo propusimos, el considerar "en sentido amplio" implica solo una demarcación en términos de presencia/ no presencia, sin considerar los sentidos puestos en escena en y por las intervenciones identificadas.

En esta sección nos proponemos desentrañar algunos de los sentidos que estas presencias ponen en circulación, es decir, nos proponemos analizar las significaciones emergentes en los discursos que como tales se encuentran en relación con el contexto sociopolítico de debate y, por lo tanto, inscriben, convocan, reclaman, asumen, determinados posicionamientos en relación con las disputas existentes en lo público en el campo de la sexualidad en general y frente al debate en particular.

Con el objetivo de profundizar el abordaje, en esta segunda instancia, realizamos entonces un análisis de los discursos pronunciados por los legisladores utilizando como corpus de trabajo aquellas intervenciones en las que detectamos marcas de lo religioso, y nos focalizamos en las maneras en las que se ponen en relación los sentidos articulados en las intervenciones con su contexto sociopolítico de producción.

En las maneras en que se activa lo religioso en la discusión de las Cámaras ${ }^{26}$ se pueden identificar al menos dos cuestiones que se profundizan a continuación: por un lado, la necesidad de encuadrar a la religión dentro del debate. Esto es, la búsqueda de definiciones que permitan determinar cuál es el lugar que lo religioso (la religión, la fe etc.) debe tener en un contexto de debate legislativo.
Por otro lado, la inscripción de lo religioso en un campo de relaciones (y diálogos) con (otras) voces y actores presentes en el espacio público, lo cual activa en los legisladores la necesidad de dar respuesta a las interpelaciones del contexto sociopolítico de debate, las que se producen centralmente en torno a la (propia) adscripción religiosa y el posicionamiento frente al proyecto de ley.

De allí que la primera cuestión que llamaremos de orden prescriptivo se asienta en la necesidad de definir el lugar de la religión o lo religioso en sentido genérico. ${ }^{27} \mathrm{La}$ segunda que llamaremos de orden interpelativo esta signada por la necesidad de definir y posicionarse respecto a actores y discursos religiosos particulares-contingentes.

\section{III.b.1. Lo prescriptivo}

El debate sobre cuál debiera ser el rol público de lo religioso, como lo dijimos previamente, tiene un lugar destacado en la política y la academia contemporáneas. El mismo se intensifica en tanto eje prescriptivo en el momento de debatir los DDSSRR ya que al ingresar estos derechos a la agenda pública, las instituciones, personas y discursos religiosos suelen ser el principal obstáculo para reformas legales sobre la sexualidad y la reproducción. Por ello, este trabajo busca profundizar el análisis sobre las formas en que el debate sobre el papel y los límites de lo religioso ingresó en la discusión parlamentaria de la Ley de Matrimonio Igualitario.

Una tensión que atraviesa el debate en general (pero que en la Cámara de Diputados encuentra una mayor persistencia) es el tratar de ordenar, definiéndolos, los ámbitos que en sistemas democráticos corresponden a la religión. Así, la necesidad de enmarcar en el debate parlamentario a la religión (genérica) se manifiesta mediante la delimitación de lo religioso y lo político.

A nivel analítico, podemos decir que lo anterior se presenta de dos maneras opuestas: por un lado, buscando separar ambos campos mediante la definición/delimitación de sus fronteras. Por otro lado, resaltando las zonas de intersección de estos campos a partir de la relativización de esas fronteras.

\footnotetext{
26. Consideramos importante señalar que si bien se presentan elementos comunes en las maneras en que lo religioso atraviesa el debate en las Cámaras, también observamos ciertas diferencias, las que pueden explicarse a partir de los acontecimientos que se sucedieron entre la primera y segunda votación. Sin embargo, en esta presentación decidimos apostar por una lectura que vincule ambas instancias pero considerando las diferencias. Por lo tanto, cada vez que observamos alguna característica que se presenta solo en una Cámara o que tiene mayor peso en una sesión, lo apuntamos.
}

27. En las intervenciones de los legisladores, estas definiciones aparecen de manera general mediante el uso de palabras como "iglesias", "religiones", "creencias", "convicciones" sin conectarlas necesariamente a alguna iglesia o religión en particular. 
En las intervenciones que buscan delimitar las fronteras entre lo religioso y lo político, las referencias a la necesidad de legislar teniendo como principio medular el "Estado laico" se vuelven relevantes en el momento de justificar la modificación del orden normativo vigente. Tanto entre quienes se manifiestan a favor como en contra de la ley, el sentido de "Estado laico" (asociado a "leyes civiles", "matrimonio civil" etc.) se pone de relieve para justificar la posición. De esta manera, el atributo de laicidad del Estado se vuelve un espacio central en las confortaciones interpretativas que se traduce en una disputa por el anclaje y determinación del sentido válido.

En esta disputa se va conformando una red de interpretaciones relacionadas con la posición defendida. Así vemos que quienes sostienen posiciones a favor de la reforma legal, el atributo de laico se vuelve significativo especialmente en contraposición con lo religioso (o el lugar que la religión debería tener en la discusión). Desde estas interpretaciones, aún cuando se reconoce la presencia de lo religioso en la cultura argentina e incluso de las instituciones religiosas ${ }^{28}$ como importantes dadoras de sentidos en la sociedad contemporánea, se considera que la presencia de la religión aparece negando la problemática en los términos en los que es discutida en el ámbito legislativo. Por esta razón, se sostiene que las convicciones religiosas, la fe etc. deberían quedar afuera del debate (y de alguna manera, limitadas al ámbito de lo privado de las personas).

Yo tengo mis creencias religiosas pero éstas no me impiden tener la certeza de que vivimos en un Estado laico, y en un Estado laico todos tenemos derecho a la igualdad ante la ley, más allá de nuestras creencias. Ésta es mi convicción democrática. ${ }^{29}$

Debemos legislar para todos y todas teniendo en cuenta que este es un país laico; que los preceptos religiosos están fuera de discusión... ${ }^{30}$

Conectado con lo anterior, también se producen articulaciones destinadas a distinguir los espacios legítimos para lo religioso y lo político (asociados a las Iglesias y al Estado respectivamente). Esta contraposición (no en sentido de oposición, sino de esferas separadas) atraviesa gran parte de las intervenciones, independientemente se trate de quienes se manifies- tan como creyentes o de quienes buscan alejarse de alguna adscripción religiosa. Estas demarcaciones sirven asimismo, para ubicar el deber ser del Estado y el propio posicionamiento en el contexto de debate:

Los argumentos religiosos son todos válidos yo los tengo-, pero me sirven para mis convicciones íntimas. Sin embargo, cuando vengo a este Senado a legislar, lo tengo que hacer sin perder de vista que hay creyentes y no creyentes. ${ }^{31}$

Para dar un abordaje desde el punto de vista del Estado, primero queremos plantear que lo que estamos tratando hoy es la modificación de leyes civiles en un Estado laico. [...]Y en ese sentido, ya hoy el matrimonio civil es absolutamente distinto a los matrimonios religiosos. En la religión católica, por ejemplo, el matrimonio es un sacramento $\mathrm{y}$ es indisoluble. En cambio, en el ámbito civil de nuestras leyes civiles tenemos el divorcio vincular y acceden a este matrimonio civil las personas de todas las religiones y también aquellas que optan por no tener religión. ${ }^{32}$

No estamos aquí para derogar o modificar ningún sacramento religioso, de ningún credo, sino para legislar en un país laico, y considero que un Estado responsable más una comunidad comprometida van a hacer un país más justo. ${ }^{33}$

Otras intervenciones ponen en escena pública sentidos que buscan relativizar las fronteras de los campos político y religioso, apelando a la vinculación entre la religión y lo cultural. Con mayor intensidad, entre quienes sostienen posiciones en contra de la ley (o a favor de proyectos alternativos, como los de unión civil) se va construyendo una argumentación con base en la presencia de lo religioso como parte de la cultura y de la propia gestación del Estado y del orden jurídico argentino.

Pero en realidad, en la historia judeocristiana, esto está sumamente vinculado. Si nosotros nos queremos olvidar absolutamente de la religión o mirar desde el positivismo las limitaciones y las regulaciones, veremos que en casi todos los códigos penales del mundo están penados el hurto, el homicidio, la violación, los abusos sexuales. De hecho, si va-

\footnotetext{
28. Aunque no necesariamente se realizan referencias a determinadas instituciones religiosas, la Iglesia católica es la que adquiere mayor visibilidad.

29. Lorena Rossi (diputada, provincia de Río Negro). Los resaltados son nuestros, salvo que se indique lo contrario.

30. Elena Corregido (senadora, provincia de Chaco).

31. Nicolás Fernández (senador, provincia de Santa Cruz).

32. Vilma Ibarra (diputada, Ciudad Autónoma de Buenos Aires).

33. María Elena Chieno (diputada, provincia de Corrientes).
} 
mos al origen de la religión judeocristiana, los Diez Mandamientos no hacen ni más ni menos que penar: no robarás, no cometerás adulterio, no violarás etcétera. O sea que por más que queramos separarlos llega un momento en que por nuestra misma historia y nuestra misma tradición tienen un argumento en común. ${ }^{34}$

Por ahí, también se dijo que no hay que mezclar las cuestiones de Dios con las del Estado. Pero fíjense que este Estado nació al amparo de Dios, que es fuente de toda razón y justicia. Entonces, los que creemos que Dios existe, lógicamente, también pensamos que rige nuestras vidas. Por eso es que, cuando actuamos, lo debemos hacer en función de ello. ${ }^{35}$

De esta manera, se articulan estrategias que utilizan como marco ciertas figuras legales que posibilitan la relativización de las fronteras. Una de las referencias es el artículo 2 de la Constitución Nacional argentina donde se afirma que "el gobierno sostiene el culto católico apostólico romano”. Esta fórmula habilita diferentes interpretaciones, por lo que entre ellas, se encuentra la sostenida por algunos sectores que afirman la necesidad de que el derecho se base en la doctrina católica. Así, la fórmula constitucional que evidencia la insuficiente separación Estado e Iglesia también es utilizada por algunos legisladores para justificar el rechazo al matrimonio parejas del mismo sexo porque contraría los principales preceptos del catolicismo.

El artículo $2^{\circ}$ de nuestra Constitución Nacional dice: "El Gobierno federal sostiene el culto católico apostólico romano." Es por eso que vengo a defender mi posición desde la fe, pero también desde el derecho. ${ }^{36}$

De allí que encontremos como justificativo de la posición, el reconocimiento de la existencia de un éthos religioso en el que se despliega lo social en general y las instituciones estatales y sus marcos normativos, en particular. Esto permite generar ciertos modos de aproximación entre las cosmovisiones religiosas y el establecimiento de los órdenes legales al proponer que ambas esferas se encuentran conectadas en valores y creencias compartidas socialmente. Este tipo de articulaciones como dijimos adquiere mayor presencia entre quienes se posicionan en contra del proyecto de ley. Principalmente en las intervenciones que buscan reservar para las parejas heterosexuales la figura legal del matrimonio (justificando la vinculación del matrimonio civil con la figura sacramental del matrimonio en el orden de lo cultural-histórico) y otorgar el reconocimiento de las uniones afectivas no heterosexuales proponiendo la creación de órdenes legales e instituciones diferentes.

\section{III.b.2. Lo interpelativo}

Si en el apartado anterior buscamos presentar el plano prescriptivo de las intervenciones en las cámaras legislativas, esto es, la necesidad de delimitar las fronteras entre lo religioso y lo político (y el derecho), en este apartado se consideran las formas en que los/ as legisladores/as inscriben su identificación religiosa como parte del debate parlamentario. Otra dimensión de la atadura religión y política que se despliega al debatirse los DDSSRR es el papel de las identidades religiosas ya que la mayoría de la población, así como de los líderes políticos, se autoidentifica como creyente. ${ }^{37}$ Diversos análisis ponen el acento sobre el papel que tienen estas identidades en el momento de votar o legislar en temas conectados con la sexualidad y la reproducción (Gerlero, 2009). Si bien ciertas construcciones de lo público requieren, como lo indicáramos previamente, de la suspensión de las creencias religiosas durante el debate parlamentario, la identificación religiosa fue desplegada (sacada del clóset) por parte de los/as legisladores/as aunque con posturas diferenciadas, incluso opuestas.

En este apartado buscamos reconocer las interdiscursividades (con las voces y los actores presentes en el espacio público) que consideramos activan en los legisladores la necesidad de otorgar una respuesta, atravesada fundamentalmente por la tensión entre la adscripción religiosa y el posicionamiento frente al proyecto de ley en discusión.

Quizás como efecto de los acontecimientos que se sucedieron pos-votación en Diputados (la intensificación de las movilizaciones callejeras tanto a favor como en contra de la ley, las audiencias públicas, el ingreso del tema con mayor intensidad en las agendas mediá-

\footnotetext{
34. Liliana Negre de Alonso (senadora, provincia de San Luis).

35. José Mayans (senador, provincia de Formosa).

36. Julio Ledesma (diputado, provincia de Buenos Aires).

37. A nivel poblacional, según la encuesta sobre "Actitudes y creencias religiosas en argentina" (Mallimaci, et al., 2008) el $91 \%$ manifiesta creer en Dios mientras que el $76 \%$ se define como católico. Más específicamente, la encuesta realizada a senadores y diputados nacionales durante el año 2010, es decir, en el momento de debate del matrimonio igualitario, informa que el 65\% de los legisladores encuestados manifiesta creer en Dios mientras que el $60 \%$ se define como católico (Esquivel y Vaggione, 2011). Esto permite observar un predominio tanto a nivel poblacional como en relación con el poder legislativo de quienes se autoidentifican como creyentes.
} 
ticas, entre otros) en el debate del Senado adquieren mayor presencia, colectivos y personas identificables y relacionados especialmente con la Iglesia católica. ${ }^{38}$

Consideramos que estas articulaciones exceden a las entidades o personas nombradas, más bien se utilizan como estrategia para delinear un posicionamiento respecto a las interpretaciones más restrictivas sostenidas y defendidas por ciertos sectores religiosos tanto a nivel de las jerarquías como de la sociedad civil. En este sentido, la explicitación de la propia adscripción religiosa es utilizada para confrontar con los posicionamientos públicos sostenidos por las jerarquías religiosas (principalmente por la Iglesia católica) en el contexto de debate, y por lo tanto afirmar desde esta confrontación una conciliación de las creencias religiosas con posiciones favorables a la ampliación de derechos.

En esta dirección, nos interesa mencionar aquí un documento epistolar firmado por el arzobispo de Buenos Aires, cardenal Jorge Bergoglio titulado "Carta a las Carmelitas", del 22 de junio (2010, Boletín Eclesiástico del Arzobispado de Buenos Aires. Num. 159, Año LII.). Este documento adquiere relevancia en el contexto del debate en la Cámara de Senadores en tanto es mencionado (o sugerido ${ }^{39}$ ) por algunos de los oradores de la sesión e incluso sirvió como argumento para conciliar adscripciones religiosas con una postura a favor de la ley. Más allá de las intenciones de la misiva, lo cual excede nuestra presentación, nos interesa subrayar que este documento se activa en el debate parlamentario como fundamento, principalmente para quienes sostienen una posición favorable a la modificación de la ley:

Yo soy un hombre católico, no practicante, pero cristiano. Me he casado y tengo hijos que están bautizados. Sin embargo, me he sentido avergonzado de las palabras de quien tendría que ser mi pastor, o sea, monseñor Bergoglio. $\mathrm{Me}$ parece que plantear que la envidia del demonio es la que quiere destruir a Dios y la que está dentro de este proyecto de ley, no corresponde a lo que tendría que ser un evangelizador. ${ }^{40}$

Dicen que hay mucha crispación. Dentro de poco, creo que por el resfriado de cualquiera, la culpa la va a tener el matrimonio Kirchner [...] crispación y a quiénes estuvieron acusando de que acá se está planteando una guerra entre Dios y el demonio; y quiénes son los demonios y quiénes representan a Dios. ${ }^{41}$

Mi formación cristiana y católica me permite preguntarme lo siguiente: ¿los papás heterosexuales que tengan o los que tuvimos hijos homosexuales, pasamos a ser instrumentos que atacamos el plan de Dios? ¿Nuestros hijos pasan a atacar el plan de Dios? ${ }^{42}$

Pero también la pertenencia religiosa es utilizada para apoyar el proyecto de ley a través de la re-inscripción de interpretaciones que buscan poner en escena la multiplicidad de visiones existentes en quienes se consideran creyentes y desde su propia identidad se manifiestan a favor del proyecto en discusión. Algunos legisladores lo hacen a partir del diálogo con voces del contexto sociopolítico de debate donde hubo quienes como miembros de la Iglesia católica se manifestaron públicamente a favor del proyecto. Un ejemplo en este sentido es el documento "Aporte al debate sobre modificaciones a la Ley de Matrimonio Civil" firmado por el Presbítero Nicolás Alessio ${ }^{43}$ como miembro de la Agrupación de Sacerdotes Enrique Angelelli, en el que brinda argumentos religiosos a favor del matrimonio entre personas del mismo sexo y pone en explícito la necesidad de reconocer la pluralidad de posicionamientos en el interior de la Iglesia católica negando la existencia de un "pensamiento único".

Así en el debate parlamentario también hubo quienes justificaron su voto favorable desde su adscripción religiosa retomando y destacando a actores del contexto o recreando y poniendo en escena su propia (re)interpretación:

Por último, como católica que soy, quiero reconocer la actitud cristiana de los sacerdotes de Córdoba, Quilmes y Mendoza que, con todo coraje y convicción, han defendido el Evangelio y la libertad de pensamiento. Han pensado, como Jesús enseñó, que el Evangelio nos hace libres y que el amor es lo único que importa. ${ }^{4}$

\footnotetext{
38. Si bien en la sesión en Diputados se realizan referencias (por ejemplo, "curas", "prelados", "iglesia" etc.); en Senadores, además de estas menciones, se intensifican nombres propios asociados principalmente a la Iglesia católica. De la misma forma, también se visibilizan (aunque sin nominación sino más bien como colectivos sin identificación) las agrupaciones de la sociedad civil que participaron de las marchas, de las audiencias públicas etc.

39. Las referencias al documento aparecen de dos maneras: a) de manera "directa", nombrando explícitamente la misiva o al cardenal Bergoglio y b) de manera "indirecta", usando paráfrasis de lo expresado en la carta como por ejemplo "guerra entre Dios y el demonio".

40. Alfredo Martínez (senador, provincia de Santa Cruz).

41. Eduardo Torres (senador, provincia de Misiones).

42. Marcelo Guinle (senador, provincia de Chubut).

43. Sacerdote católico, provincia de Córdoba, Argentina.

44. Elena Corregido (senadora, provincia de Chaco).43. Sacerdote católico, provincia de Córdoba, Argentina.
} 
Yo creo en Dios, en Cristo, soy católico, tengo familia, soy heterosexual y creo en un Dios con un corazón así grandote y no en alguien que además me permita llegar a la conclusión de que los homosexuales no son hijos de Dios. ${ }^{45}$

[...] y que porque soy católica y cristiana, adhiero profundamente a la fe religiosa y a los principios fundamentales que, para mí, tiene el cristianismo, que son la tolerancia, el amor al prójimo, la solidaridad y la protección al desvalido. ${ }^{46}$

Estos posicionamientos buscan reinscribir (por ende, sin excluirlas de la discusión) las (propias) creencias religiosas con una posición a favor de la ley poniendo en explícito (en el espacio público) sentidos que visibilizan la heterogeneidad y complejidad de las identidades religiosas. De esta forma, mediante la búsqueda de (re)definiciones y (re)- apropiaciones de sentidos del orden de lo religioso, se ponen en escena las múltiples maneras de conciliar creencias religiosas con posiciones favorables a una ampliación de derechos sexuales y reproductivos (Vaggione, 2008b; Peñas Defago y Sgró Ruata, 2009).

En dirección opuesta a los posicionamientos anteriores, los argumentos religiosos también se utilizaron para fundamentar la oposición a la iniciativa. Estos argumentos se presentan vehiculizados desde -al menos- dos operaciones: una explícita, colocando en el mismo plano los fundamentos de las intervenciones con los de las declaraciones o documentos difundidos por instituciones religiosas, y otra implícita que si bien busca alejarse de fundamentos de orden religioso, defiende y sostiene significaciones conformes a lo sostenido públicamente por los discursos oficiales de las jerarquías religiosas.

En la primera dirección, algunas de las estrategias desplegadas se basan en poner en escena textos directamente vinculados con la religión a través del uso de pasajes de la Biblia o citas a documentos del Vaticano. Estos argumentos se articulan tanto desde lo normativo como desde lo programático. Es decir, apelan tanto a las nociones sostenidas por los discursos oficiales de las iglesias (con mayor relevancia, a los de la Iglesia católica) como a las formas de actuar sugeridas por ellas. Este uso no es tan frecuente y tiene mayor presencia en la sesión de Diputados, sin embargo, consideramos que cabe mencionarlo por lo menos, en tanto otras de las formas directas de traer a escena pública preceptos religiosos al debate parlamentario. Por ejemplo:

Para concluir, voy a citar a Su Santidad el Papa Benedicto XVI, cuando era prefecto de la Congregación para la Doctrina de la Fe. El Sumo Pontífice dijo que en el caso de que en una asamblea legislativa se proponga por primera vez un proyecto de ley a favor de la legalización de las uniones homosexuales, el parlamentario católico tiene el deber moral de expresar clara y públicamente su desacuerdo y votar en contra del proyecto de ley. Conceder el sufragio o el propio voto a un texto legislativo tan nocivo del bien común de la sociedad y de la familia es un acto gravemente inmoral. ${ }^{47}$

El Papa Juan Pablo II en su Exhortación Apostólica "Familiaris Consortio" de noviembre del año 1981, escrita a la luz de lo que la Iglesia avizoraba como un avance sobre la institución de la familia cristiana, indicaba que: "La sexualidad, mediante la cual el hombre y la mujer se dan uno a otro con los actos propios y exclusivos de los esposos, no es algo puramente biológico sino que afecta el núcleo íntimo de la persona humana en cuanto tal". 48

Otras estrategias de oposición recurren al uso de argumentos seculares (Vaggione, 2009b). Si bien desde estas posiciones se defienden concepciones tradicionales como la familia nuclear basada en el matrimonio heterosexual (reproductivo) en conexión con la cosmovisión difundida y defendida por miembros de las iglesias y por las organizaciones civiles que se manifestaron en oposición a la iniciativa, ${ }^{49}$ se busca asentar el argumento en posturas alejadas de preceptos religiosos adoptando mas bien argumentos jurídicos.

Ante todo me gustaría aclarar que no lo voy a hacer desde un punto de vista confesional, más allá de que estoy muy orgullosa de mi confesión religiosa, sino sobre la base de consideraciones de hecho y de derecho que procuraré sintetizar [...] El matrimonio es una institución que ha sido conocida a lo largo de la historia de las civilizaciones

\footnotetext{
45. Nicolás Fernández (senador, provincia de Santa Cruz).

46. Lucía Corpacci (senadora, provincia de Catamarca).

47. Julio Ledesma (diputado, provincia de Buenos Aires).

48. Roberto Robledo (diputado, provincia de La Pampa).

49. Organizaciones (auto)denominadas pro-vida y pro-familia que articulan una práctica pública política alentada por un posicionamiento conservador en relación con la familia y la sexualidad que en el contexto de debate sobre la reforma de la institución matrimonial participaron activamente en la conformación de un abanico opositor a la ley.
} 
y de las distintas religiones como la unión de dos personas de distinto sexo que se unen para disfrutar del amor que se profesan y compartir el pasar la vida. Generalmente este sentimiento se traduce en la prolongación a través de la procreación para garantizar la supervivencia de la especie y fundar una familia, que es la célula madre de la sociedad..$^{50}$

La Ley Fundamental, la que fija los límites y define las relaciones entre los poderes Legislativo, Ejecutivo y Judicial del Estado, la que establece las bases para su gobierno y ordenación de las instituciones en que tales poderes se asientan y que también garantiza al pueblo aquellos derechos y libertades más esenciales, tiene como uno de sus principios rectores el sostenimiento del culto católico, y junto a él, de los institutos que el credo protege. ${ }^{51}$

De esta manera, en relación con los argumentos de oposición desplegados en el debate parlamentario, es posible distinguir tanto quienes refieren explícitamente a su adscripción religiosa para votar en contra de la iniciativa como quienes buscan oponerse al proyecto desde la articulación de fundamentos con base en lo exclusivamente jurídico, pero sosteniendo visiones acordes a las difundidas y sostenidas en el contexto de discusión por actores e instituciones religiosas.

\section{Líneas de Cierre}

En este artículo nos propusimos considerar las (re)articulaciones entre lo religioso y lo político tomando el debate parlamentario sobre matrimonio entre parejas del mismo sexo en Argentina como un escenario privilegiado para abordar y pensar estas relaciones.

La politización de la sexualidad lograda en gran medida por los movimientos feministas y por la diversidad sexual, puso en evidencia que lejos de desaparecer, la influencia política de las principales religiones se ha reactivado frente a las agendas de estos movimientos. Las reformas en el campo de DDSSRR nos enfrentan a la necesidad de repensar los cruces entre lo religioso y lo político en las sociedades contemporáneas, suspendiendo miradas convencionales para asumir nuevos desafíos teóricos y empíricos.

En particular, el debate por los DDSSRR en Latinoamérica requiere de un análisis crítico sobre las variadas formas en que lo religioso, en particular el catolicismo, construyó (y construye) el orden sexual. Construcción que se manifiesta en la influencia sedimentada de la jerarquía católica no solo sobre los principales poderes del Estado (su materialización en el derecho) sino también en ciertos rasgos culturales devenidos en orden moral universalizado (y universalizante).

Los desafíos de la presencia pública de las religiones a los análisis sobre la política sexual son principalmente de dos tipos que atraviesan este artículo de manera parcial. Por un lado, es necesario profundizar nuestra comprensión sobre las formas en que lo religioso se vuelve materialidad política en el momento de debatir la sexualidad. Sin dudas, reflexiones en torno a la separación Estado e Iglesia, la laicidad o la secularización como procesos incompletos, ofrecen una clave importante de lectura pero las influencias religiosas sobre la política sexual se manifiestan también de maneras más complejas y diversas. Por otro lado, también es importante suspender la construcción de lo religioso como una influencia necesariamente negativa para los DDSSRR. Si bien la presencia pública de las principales instituciones religiosas es un obstáculo para el debate y la democratización de la sexualidad, es necesario considerar aquellas manifestaciones de lo religioso que, por el contrario, tienen un efecto cultural y político favorable al cambio legal.

El ingreso al debate legislativo del "matrimonio igualitario" fue acompañado, también, por un ingreso de lo religioso como marcas que impregnan el debate tanto en Diputados como Senadores. Más allá del espacio que lo religioso debería tener en el Parlamento, una mayoría de los/as legisladores/ as evidencian en sus discursos que debatir las formas de regular la sexualidad en general, y el matrimonio en particular, implica de manera inevitable incluir lo religioso como dimensión del debate. Frente a la herencia de la modernidad intentando trazar de manera clara las fronteras entre lo religioso y lo político, los debates públicos sobre sexualidad ponen de relieve precisamente el repensar la porosidad y artificialidad de esas fronteras.

Así, las identificaciones religiosas o la discusión sobre las fronteras de lo religioso, por ejemplo, ingresan al debate parlamentario como ejes cruciales desde donde debatir la sexualidad. Sin embargo, las referencias a estos ejes adquieren complejidad puesto que son articuladas independientemente de la posición adoptada frente a la ley: los/as legisladores/as traen a colación su identificación con el catolicismo tanto para apoyar como para rechazar el proyecto. En ambas circunstancias se hace referencia a construcciones sociopolíticas opuestas sobre el catolicismo. De modo similar, la apelación a la laicidad como forma de demarcación de fronteras entre religión y política se realiza tanto para justificar el reconocimiento de derecho para parejas del mismo sexo como para rechazarlos. 
Mas allá de las construcciones normativas sobre la democracia que proponen la suspensión de lo religioso, el debate parlamentario sobre la sexualidad está, al contrario, plagado de marcas y referencias a lo religioso. Sin embargo, estas marcas y referencias juegan de manera compleja, incluso opuestas, respecto a los DDSSRR. Aunque excluir lo religioso del debate parlamentario no parece un camino posible, resca-

\section{Referencias}

ALDAO, Martín y CLÉRICO, Laura (Coord). Matrimonio igualitario. Perspectivas sociales, políticas y jurídicas. Buenos Aires: EUDEBA, 2010.

ASAD, Talad. The formation of the secular. Christianity, Islam, Modernity. California: Stanford University Press, 2003.

ALTHAUS-REID, Marcella. Indecent Theology. Theological Perversions in Sex, Gender and Politics. London: Routledge, 2001.

BLANCARTE, Roberto. (Coord.) Los Retos de la Laicidad y la Secularización en el Mundo Contemporáneo. México: Colmex, 2008.

CAMPOS GOMEZ, Edlaine. A religião em discurso: a retórica parlamentar sobre o aborto. In: DiAs DUARTE, Luiz Fernando; CAMPOS GOMES, Edlaine; AISENGART MENEZES, Rachel; NATIVIDADE, Marcelo (Orgs.). Valores religiosos e Projetos de Lei no Brasil. Rio de Janeiro: Garamond, 2009.

CASANOVA, José. Public Religions in the Modern World. Chicago: University of Chicago Press, 1994.

CATÓLICAS POR EL DERECHO A DECIDIR (CDD. Actitudes de los Católicos sobre Derechos Reproductivos, Iglesia-Estado y Temas Relacionados. Tres Encuestas Nacionales en Bolivia, Colombia y México, 2003.

CONNOLly, William E. Why I Am Not a Secularist. Minneapolis, MN: University of Minnesota Press, 1999.

COUTO, M. T. Gênero e comportamento reprodutivo em contexto de famílias em pluralismo religioso. In: HEILBORN, M.L. et al. Sexualidade, família e ethos religioso. Rio de Janeiro: Garamond, 2005.

DA COSTA, Néstor (Org.). Laicidad en América Latina $y$ Europa. Repensando lo religioso entre lo público y lo privado en el siglo XXI. Montevideo: Centro Latinoamericano de Economía Humana, 2006.

DIDES C., Claudia (Comp.). Diálogos Sur-Sur sobre religión, derechos y salud sexual y reproductiva: los casos de Argentina, Colombia, Chile y Perú. Santiago de Chile: Universidad Academia de Humanismo Cristiano- PROGÉNERO, 2004.

DIDES C., Claudia; BENAVENTE R., M. Cristina; SÁEZ A. Isabel; MORÁN F., José Manuel. Estudio de opinión pública sobre aborto $y$ derechos sexuales $y$ reproductivos en Brasil, Chile, México y Nicaragua. Santiago de Chile: FLACSO-Chile, 2011. tar y destacar su complejidad es una posibilidad tanto para los análisis como para la política sexual.

La persistencia de las marcas religiosas en el debate parlamentario, como vimos en este trabajo, tal vez invite a repensar las articulaciones entre lo político y lo religioso sobre la base de la visibilización de sus interconexiones en un entramado que excede la relación en términos de exclusión.

ESQUIVEL, Juan Cruz y VAGGIONE Juan Marco (Dirs.) Religión y Política: Influencia de las convicciones religiosas en los/as Diputados/as y Senadores/as Nacionales en Argentina. Informe de investigación. Buenos Aires: CEILPIETTE/ CONICET, 2011.

GALlGHER, John; BULL, Chris. Perfect Enemies. The Religious Right, the Gay Movement, and the Politics of the 1990s. Lanham: Madison Books, 2001.

GERLERO, Mario. Derecho a la sexualidad. Buenos Aires: Grinberg, 2009.

GROSSI, Miriam; UZIEL, Anna Paula; MELLO Luiz (Eds.) Conjugalidades, parentalidades e identidades lésbicas, gays e travestis. Rio de Janeiro: Garamond, 2007.

GUZMAN STEIN, Laura. The politics of implementing women's rights in Catholic countries in Latin American. In: BAYES, Jane y TOHIDI, Nayereh. Globalization, gender, and religion: the politics of women's rights in Catholic and Muslim contexts. New York: Palgrave, 2001.

GONZALEZ RUIZ, Edgar. Cruces y Sombras. Perfiles del conservadurismo en América Latina. México, 2005.

HUACO PALOMINO, Marco Antonio. Relaciones Iglesia-Estado en Perú: entre el estado pluriconfesional y el estado laico. In: BLANCARTE, Roberto. Los retos de la laicidad y la secularización en el mundo contemporáneo. México: Colegio de México, 2008.

HABERMAS, Jurgen. Entre naturalismo y religión. Barcelona: Paidós, 2006.

HTUN Mala. Sex and the State. Abortion, Divorce and the Family under Latin American Dictatorships and Democracies. Cambridge: Cambridge University Press, 2003.

JONES, Daniel y CUNIAL, Santiago. Evangélicos contra el "matrimonio homosexual" en Argentina: el activismo político de la federación Alianza Cristiana de Iglesias Evangélicas de la República Argentina (ACIERA). In: PEÑAS DEFAGO, María Angélica y VAGGIONE, Juan Marco (Comps.) Actores y discursos conservadores en los debates sobre sexualidad y reproducción en Argentina. Córdoba: Ferreyra Editor/ CDD, 2011.

MACHADO, Maria das Dores Campos. Neopentecostalismo: continuidades e descontinuidades nas representações e relações de poder entre os gêneros. In: Caminhos. Goiânia: UCG, 2003.

Política e religião. Rio de Janeiro: Fundação Getúlio Vargas, 2006. 
MALLIMACI, Fortunato; ESQUIVEL, Juan Cruz; IRRAZABAL, Gabriela. Primera Encuesta sobre Creencias y Actitudes Religiosas. Informe de investigación. Buenos Aires: CEIL-PIETTE CONICET, 2008.

MALLIMACI, Fortunato. Excepcionalidad y secularizaciones múltiples: hacia otro análisis entre religión y política. In: MALLIMACI, F. (Ed.) Religión y Política. Perspectivas desde América latina y Europa. Buenos Aires: Biblos, 2008.

MUJICA, Jaris. Economía Política del Cuerpo. La reestructuración de los grupos conservadores y el biopoder. Lima: PROMSEX, 2007.

MUSSKOPF, Andre. S. Talar Rosa - Homossexuais e o ministério na Igreja. São Leopoldo: Oikos, 2005.

NUGENT, Guillermo. De la sociedad doméstica a la sociedad civil. Una narración de la situación de los derechos sexuales y reproductivos en el Perú. In: DIDES C. (Comp.), Diálogos Sur-Sur sobre Religión, Derechos $y$ Salud Sexual y Reproductiva. Los casos de Argentina, Colombia, Chile y Perú. Santiago de Chile: Academia de Humanismo Cristiano- PROGÉNERO, 2004.

PEÑAS DEFAGO, Ma. Angélica y VAGGIONE, Juan Marco (Comps.). Actores y discursos conservadores en los debates sobre sexualidad y reproducción en Argentina. Córdoba: Ferreyra Editor/ CDD, 2011.

PEÑAS DEFAGO, Ma. Angélica y SGRÓ RUATA, Ma. Candelaria. Género y religión. Pluralismos y disidencias religiosas. Córdoba: Ferreyra Editor/ CDD, 2009.

RAWLS, John. Liberalismo Político. México: UNAM/ Fondo de Cultura Económica, 1995.

SGRÓ RUATA Ma. Candelaria; RABBIA, Hugo; IOSA, Tomás; MANZO, Mariana; CAMPANA, Maximiliano;
MORÁN FAUNDES, José Manuel. El debate sobre el matrimonio igualitario en Córdoba. Actores, estrategias y discursos. Córdoba: Ferreyra Editor/ CDD, 2011.

UZIEL, Anna Paula. Homosexualidade e adoção. Rio de Janeiro: Garamond, 2007.

VAGGIONE, Juan Marco. Las familias más allá de la heteronormatividad. In: MOTTA, Cristina y SÁEZ, Macarena. La mirada de los jueces. Género en la jurisprudencia latinoamericana. Bogotá: Siglo del Hombre Editores, 2008a.

Diversidad sexual y religión. Córdoba: Ferreyra Editor/CDD, 2008b.

- Religión, sexualidad y política. Sexuality Policy

Watch, Diálogos Latinoamericanos sobre Sexualidad $y$ Geopolítica, 2009a. Disponible en: http://www.sxpolitics. org/es/?p=1000. Acceso: 7 abr. 2012.

La sexualidad en el mundo post secular. El activismo religioso y los derechos sexuales y reproductivos. In: GERLERO, Mario Silvio (Coord.). Derecho a la Sexualidad. Buenos Aires: Grinberg, 2009b.

(Comp.) El Activismo religioso conservador en Latinoamérica. Córdoba: Ferreyra Editor/CDD, 2010.

Sexual rights and religion. Same sex-marriage and lawmakers catholic identity in Argentina. Miami Law Review, vol. 65, n. 3, p. 935-953, 2011.

VASSALLO, Marta (Comp.) En nombre la vida. Argentina: Católicas por el Derecho a Decidir, 2005.

VERÓN, Eliseo. La semiosis social. Barcelona: Gedisa, 1993.

VRIES, Hent de; SULLIVAN, Lawrence (Eds.). Political theologies. Public religions in a post-secular world. New York: Fordham University Press, 2006.

\title{
Religious marks on sexual politics: legislative debate and same-sex marriage in Argentina
}

\begin{abstract}
Public debates on sexuality and reproduction show the complex connections between religion and politics in contemporary democracies. This work proposes to explore the presence of the religious in the parliamentary debates on same-sex marriage in Argentina (2010) and to analyze the meanings deployed by lawmaker interventions in order to comprehend the re-articulations between religion and politics. Questioning the heteronormativity of the institution of marriage also involves to put in tension and visibilize its christian genealogy. Thus, the parliamentary debate becomes a privileged stage to address the political power of religion. The political perdurability of religion challenges the study of sexuality not only because it is a growing area of debate in Latin America but also because sexuality is a field where major religious institutions are not willing to give up their social and political influence.
\end{abstract}

Key words: sexuality, religion, parliamentary debate, same sex marriage. 


\section{As marcas religiosas na política sexual: debate legislativo e casamento entre pessoas do mesmo sexo na Argentina}

\section{Resumo}

Os debates públicos sobre a sexualidade e reprodução mostram redes complexas entre religião e política em nossas democracias contemporâneas. Este trabalho procura indagar a presença da religião no debate parlamentar sobre o casamento entre pessoas do mesmo sexo na Argentina (2010) e analisar os sentidos presentes nas intervenções dos parlamentares para compreender as (re)articulações entre religião e política. Pôr em causa a heteronormatividade da instituição do casamento também envolve colocar em tensão e tornar visível sua genealogia cristã. Dessa forma, o debate parlamentar torna-se um palco privilegiado para abordar o poder político da religião. A permanência do religioso na política desafia as pesquisas sobre sexualidade não só porque é uma área de debate crescente na América Latina mas porque a sexualidade é uma arena em que as principais instituições religiosas não estão dispostas a desistir de sua influência social e política.

Palavras-chave: sexualidade, religião, debate parlamentar, casamento entre pessoas do mesmo sexo.

Data de recebimento do artigo: 30/04/2012

Data de aprovação do artigo: 20/07/2012 